\title{
Locally Released Norepinephrine in the Oxygen-Dependent Regulation of Vascular Tone of Human Umbilical Vein
}

\author{
EVA MILDENBERGER, GÜNTER SIEGEL, AND HANS T. VERSMOLD \\ Department of Pediatrics [E.M., H.T.V.], Universitätsklinikum Benjamin Franklin and Biophysical \\ Research Group [G.S.], Institute of Physiology, Freie Universität 12200 Berlin, Berlin, Germany
}

\begin{abstract}
ABST
In a previous study, human umbilical vein preparations con-
stricted at $\mathrm{Po}_{2}$ values above the physiologic intrauterine $\mathrm{Po}_{2}$
range and dilated at hypoxia. Denudation of the endothelium
reversed the hypoxic vasodilatation only, suggesting the release
of a nonendothelial vasoconstrictor. We therefore hypothesized
that norepinephrine from adrenergic nerve terminals could be
responsible for the observed constricting effects. We measured
intracellular membrane potential and isometric tension of human
umbilical vein strips with and without functional adrenergic
denervation by $6-\mathrm{OH}-\mathrm{dopamine}$ during variation of Po $\mathrm{O}_{2}$. With
$\mathrm{Po}_{2}$ increasing from 5 to $104 \mathrm{~mm} \mathrm{Hg}$, intact preparations depo-
larized of from $-58.6 \pm 1.1 \mathrm{mV}$ (SEM) to $-53.3 \pm 1.0 \mathrm{mV}(p$
$<0.001)$ and isometric tension increased from $0.673 \pm 0.037 \mathrm{~g}$
to $0.825 \pm 0.044 \mathrm{~g}(p<0.02)$. Intact preparations pretreated
with 6-OH-dopamine depolarized from $-58.0 \pm 0.5 \mathrm{mV}$ to
\end{abstract}
$-55.8 \pm 0.6 \mathrm{mV}(p<0.01)$, and isometric tension increased from $0.598 \pm 0.040 \mathrm{~g}$ to $0.661 \pm 0.018 \mathrm{~g}(p<0.02)$. At $\mathrm{Po}_{2}$ values above the physiologic intrauterine umbilical venous $\mathrm{Po}_{2}$ range, membrane potential and isometric tension were significantly lower in preparations with 6-OH-dopamine pretreatment compared with matched controls $(p<0.05)$. Denudation of the endothelium reversed the hypoxic hyperpolarization and vasodilatation observed in intact preparations. However, membrane potential and isometric tension were not different between endothelium-denuded preparations with and without 6-OH-dopamine pretreatment. We conclude that locally released norepinephrine contributes to the depolarization and vasoconstriction of the human umbilical vein at hyperoxia but does not antagonize the endothelium-dependent vasodilation at hypoxia. (Pediatr Res 55: 267-272, 2004)
The contribution of vascular tone of the umbilical vein to the regulation of blood flow from the placenta to the fetus had been regarded as negligible, because the umbilical vein was thought to be maximally dilated already at resting conditions $(1,2)$. However, in a recent study, we demonstrated that human umbilical vein was far from being a passive conduit but was able to adjust its vascular tone in response to changes in local $\mathrm{Po}_{2}$ (3). Increasing $\mathrm{Po}_{2}$ to values above the range present under physiologic intrauterine conditions resulted in constriction of human umbilical vein vascular strips, whereas hypoxia led to vasodilation. In endothelium-denuded preparations, we saw not only a lack of hypoxic vasodilatation but also an increase in isometric tension at low $\mathrm{Po}_{2}$ values. These findings were consistent with the action of a vasoconstricting factor, which resulted in human umbilical vein vasoconstriction at hyperoxia and which was more than antagonized by endothelial factors mediating hypoxic vasodilatation [e.g. prostacyclin (4), nitric

Received April 23, 2003; accepted July 29, 2003.

Correspondence: Eva Mildenberger, M.D., Kinderklinik, Universitätsklinikum Benjamin Franklin, Hindenburgdamm 30, 12200 Berlin, Germany; e-mail: eva.mildenberger@medizin.fu-berlin.de

DOI: 10.1203/01.PDR.0000100907.68842.A7 oxide (5), endothelium-derived hyperpolarizing factor $(6,7)$, the endothelin-B receptor-mediated actions of endothelin (8)].

We hypothesized that endogenous norepinephrine, released from adrenergic nerve terminals that remain in the vessel wall after dissection procedures (9), could account for the observed vasoconstricting effects. However, there is conflicting evidence from anatomical studies whether the human umbilical vein has any autonomic innervation in the extracorporeal part of the cord vessel $(10-15)$. In this functional study, pretreatment of human umbilical vein preparations with 6-OH-dopamine was chosen to produce functional in vitro adrenergic denervation (9). We thus investigated a possible depolarizing and vasoconstricting contribution of locally released norepinephrine to the oxygen-dependent regulation of human umbilical vein vascular tone. On the one hand, we tested whether the depolarization and increase in isometric tension of intact preparations at high $\mathrm{PO}_{2}$ were inhibited by pretreatment with 6-OH-dopamine. On the other hand, we tested whether the depolarization and increase in isometric tension of endothelium-denuded preparations at low $\mathrm{PO}_{2}$ were diminished after pretreatment with 6-OH-dopamine. 


\section{METHODS}

Vessel dissection. Human umbilical cords were obtained from normal full-term deliveries after uneventful pregnancies with no evidence of hypertension in pregnancy or other pregnancy-related diseases. Additional characteristics of the newborns are summarized in Table 1 . The study was approved by the local ethical committee. Within the first minutes of birth, cord segments were cut at least $10 \mathrm{~cm}$ from the infants, because this part of the human umbilical vein is thought definitely to be devoid of nerves $(11,15)$. Segments were placed into a modified Krebs solution (in mmol/L: $151 \mathrm{Na}^{+}, 4.69 \mathrm{~K}^{+}, 2.52 \mathrm{Ca}^{2+}$, $1.1 \mathrm{Mg}^{2+}, 145 \mathrm{Cl}^{-}, 16.3 \mathrm{HCO}_{3}{ }^{-}, 1.38 \mathrm{H}_{2} \mathrm{PO}_{4}{ }^{-}$, and 7.7 glucose) and stored at $4^{\circ} \mathrm{C}$ for less than $48 \mathrm{~h}$ until the experiments were done. Systematic studies had shown that up to $3 \mathrm{~d}$ of storage of blood vessels under these conditions does not affect vessel function (16). At the end of our experiments, we added $0.05 \mathrm{M}$ of $\mathrm{KCl}$ to the bath solution to test the viability of the preparations. All preparations responded with vigorous contractions.

After carefully separating the vein from the Wharton's jelly, vascular rings, $0.5 \mathrm{~cm}$ in height, were allowed to equilibrate in Krebs solution gassed with $4 \%$ oxygen, $5 \%$ carbon dioxide, and balance nitrogen at $37^{\circ} \mathrm{C}$ for $2 \mathrm{~h}$. Vascular rings were then cut lengthwise to create vascular strips.

Removal of the endothelium. For experiments with endothelium-denuded preparations, the endothelial layer was gently scraped off by scalpel just before the experiments. In a previous study, we had confirmed the effectiveness of our method to remove completely the endothelium as well as the integrity of the endothelium in the intact preparations (17).

Registration of isometric tension and of intracellular membrane potential. Vascular strips were attached to an isometric tension measuring device (KWS 522.C, K 52 C; Hottinger Baldwin, Darmstadt, Germany) recording the tension developed by the circularly oriented smooth muscle cells, which provide the main portion of the muscular layer of the umbilical vein vessel wall (18). Specimens were superfused in a bathing chamber by Krebs solution with a constant flow of $30 \mathrm{~mL} / \mathrm{min}$, applying a pretension of $1 \mathrm{~g}$ [equivalent to the wall stress of human umbilical vein under resting conditions according to the LaPlace relationship applied to a cylindric vessel (19)]. This pretension was adjusted repeatedly during an initial period of $5 \mathrm{~min}$.

Table 1. Characteristics of the newborns from whom the umbilical cords were obtained

\begin{tabular}{lccc}
\hline & Sex & $\begin{array}{c}\text { Gestational age } \\
(\text { wk) median } \\
(\text { range)* }\end{array}$ & $\begin{array}{c}\text { Birth weight (g) } \\
\text { median (range)* }\end{array}$ \\
\hline $\begin{array}{l}\text { Intact controls } \\
(n=29)\end{array}$ & 16 girls, 13 boys & $39(37-42)$ & $3570(2650-4370) \dagger$ \\
$\begin{array}{c}\text { Endothelium- } \\
\text { denuded controls } \\
(n=23)\end{array}$ & 13 girls, 10 boys & $39(37-40)$ & $3240(2650-4650) \dagger$ \\
\hline
\end{tabular}

* Gestational age and birth weight were not different between intact and endothelium-denuded controls.

$\dagger$ All appropriate for gestational age, except five large-for-gestational-age newborns.

$\ddagger$ All appropriate for gestational age, except three large-for-gestational-age newborns.
To record intracellular membrane potential simultaneously with mechanical tension, we inserted glass microelectrodes filled with $3 \mathrm{M}$ of $\mathrm{KCl}$ into the venous smooth muscle cells from the intimal surface by means of a micromanipulator (19, 20). The electrodes were shielded to just below the tips. Their resistances ranged from 60 to $100 \mathrm{M} \Omega$. Membrane potential was displayed at a large-screen oscilloscope (SGM 43 BN 901 S/H 293; Knott, Munich, Germany) and recorded by a personal computer. A sudden negative potential change was used as the criterion of a successful intracellular insertion, which reverted to zero upon withdrawal of the microelectrode.

To ensure that membrane potential recordings were derived from vascular smooth muscle cells, we excluded values $>-45$ $\mathrm{mV}$ from our final analysis ( $<5 \%$ of all recordings), because cultured human umbilical vein endothelial cells generate a resting potential of $-25 \mathrm{mV}(21,22)$, whereas human venous smooth muscle cells generate a resting potential more negative than $-50 \mathrm{mV}(23)$.

Functional adrenergic denervation with 6-OH-dopamine. Specimens were pretreated with 6-OH-dopamine (6-hydroxydopamine hydrochloride; Sigma Chemical Co.-Aldrich Chemie, Taufkirchen, Germany) dissolved in Krebs solution at a concentration of $300 \mu \mathrm{g} / \mathrm{mL}$ according to the protocol of Aprigliano and Hermsmeyer (9), to produce functional adrenergic denervation.

Experimental protocol. Krebs solutions to superfuse the vessel preparations were bubbled by gas mixtures of $5 \%$ carbon dioxide, yielding a $\mathrm{PCO}_{2}$ of $40 \mathrm{~mm} \mathrm{Hg}$; by oxygen concentrations of $0,2,4,8$, or $14 \%$; and by balance nitrogen in individual reservoirs. Gas flows to the reservoirs were adjusted to a constant rate by individual flow meters. A five-way stop cock allowed the observer to switch instantaneously from one equilibrated superfusate to another, maintaining a flow of 30 $\mathrm{mL} / \mathrm{min}$ and thus to stepwise vary $\mathrm{Po}_{2}$ between $5,22,39,68$, and $104 \mathrm{~mm} \mathrm{Hg}$. Gas partial pressures were measured in the Krebs solution of the bathing chamber just above the specimens by a combined $\mathrm{Po}_{2} / \mathrm{PCO}_{2}$ electrode (TCM 3; Radiometer, Copenhagen, Denmark). Temperature was kept at $37^{\circ} \mathrm{C}$ and $\mathrm{pH}$ between 7.20 and 7.40. In individual series of experiments with matched pairs of untreated control preparations and preparations pretreated with 6-OH-dopamine, variations of $\mathrm{pH}$ ranged from 0.04 to 0.11 . Experiments were started at a $\mathrm{Po}_{2}$ of $39 \mathrm{~mm}$ $\mathrm{Hg}$, i.e. a value close to the physiologic human umbilical venous $\mathrm{PO}_{2}$ range [22 to $\left.35 \mathrm{~mm} \mathrm{Hg}(24)\right]$. Vessel strips were then exposed to first decreasing ( 39 to $5 \mathrm{~mm} \mathrm{Hg}$ ), then increasing ( 5 to $104 \mathrm{~mm} \mathrm{Hg}$ ), and finally again decreasing (104 to $39 \mathrm{~mm} \mathrm{Hg}$ ) $\mathrm{Po}_{2}$ for $15 \mathrm{~min}$ each, and isometric tension was recorded continuously. Isometric tension values at the end of a period of $15 \mathrm{~min}$ of exposure to the respective $\mathrm{PO}_{2}$ were averaged in each experiment. Intracellular membrane potential of multiple individual smooth muscle cells was recorded by individual impalements, lasting from seconds to minutes. Membrane potential values recorded during the second half of a period of 15 min of exposure of the preparations to the respective $\mathrm{PO}_{2}$ were averaged. The same protocol was applied in experiments with preparations pretreated with 6-OH-dopamine. 
Membrane potential and isometric tension of 29 intact and 23 endothelium-denuded human umbilical vein preparations (untreated controls) were recorded. In addition, we studied five intact and five endothelium-denuded preparations with functional adrenergic denervation with 6-OH-dopamine. For experiments with and without 6-OH-dopamine pretreatment, we used vessel strips cut from the same umbilical cords (matched pairs), because the isometric tension generated by a vessel preparation depends on smooth muscle cell mass, and different umbilical veins have different muscle masses. Thus, isometric tension of the intact and endothelium-denuded preparations pretreated with 6-OH-dopamine were compared with that of their individual controls without 6-OH-dopamine treatment. We had difficulties obtaining a sufficient number of reliable recordings of membrane potential in the matched control preparations. However, the generation of membrane potential by an individual smooth muscle cell does not depend on the total muscle cell mass of a vessel preparation. We therefore thought it reasonable to compare membrane potential recordings of the five intact preparations pretreated with 6-OH-dopamine with those of a control group consisting of all 29 intact human umbilical vein preparations and to compare membrane potential recordings of the five endothelium-denuded preparations pretreated with 6-OH-dopamine with those of a control group consisting of all 23 endothelium-denuded preparations without pretreatment.

Statistical analysis. Results are expressed as mean \pm SEM. For statistical analysis, we used linear regression analysis, ANOVA, and the paired $t$ test for comparison of treated preparations with their respective matched controls. Differences were considered statistically significant at $p<0.05$.

\section{RESULTS}

\section{Intact Human Umbilical Vein Preparations}

Untreated intact preparations. With $\mathrm{Po}_{2}$ increasing from 5 to $104 \mathrm{~mm} \mathrm{Hg}$, smooth muscle cell membranes of untreated intact human umbilical vein preparations $(n=29)$ depolarized from $-58.6 \pm 1.1 \mathrm{mV}$ to $-53.3 \pm 1.0 \mathrm{mV}(p<0.001)$ and isometric tension increased from $0.673 \pm 0.037 \mathrm{~g}$ to $0.825 \pm$ $0.044 \mathrm{~g}(p<0.02 ;$ Fig. 1$)$. The changes in membrane potential and isometric tension were most pronounced between 22 and $39 \mathrm{~mm} \mathrm{Hg} \mathrm{Po}{ }_{2}$, a range covering the physiologic intrauterine umbilical venous $\mathrm{PO}_{2}$ range (24). There was a linear overall correlation between isometric tension and intracellular membrane potential at all $\mathrm{Po}_{2}$ values investigated $(\mathrm{y}=0.030 \mathrm{x}+$ $2.41, r^{2}=0.99$, data not shown graphically).

Intact preparations pretreated with 6-OH-dopamine. With $\mathrm{Po}_{2}$ increasing from 5 to $104 \mathrm{~mm} \mathrm{Hg}$, smooth muscle cell membranes of intact human umbilical vein preparations pretreated with 6-OH-dopamine $(n=5)$ depolarized from -58.0 $\pm 0.5 \mathrm{mV}$ to $-55.8 \pm 0.6 \mathrm{mV}(p<0.01$; Fig. 2$)$. Between $\mathrm{Po}_{2}$ values of 5 and $39 \mathrm{~mm} \mathrm{Hg}$, i.e. values below and within the $\mathrm{Po}_{2}$ range present under physiologic conditions, vascular smooth muscle cell membrane potential of intact preparations with and without 6-OH-dopamine pretreatment was not statistically different. Between $\mathrm{PO}_{2} 68$ and $104 \mathrm{~mm} \mathrm{Hg}$, i.e. values above the physiologic intrauterine umbilical venous $\mathrm{Po}_{2}$ range, mem-
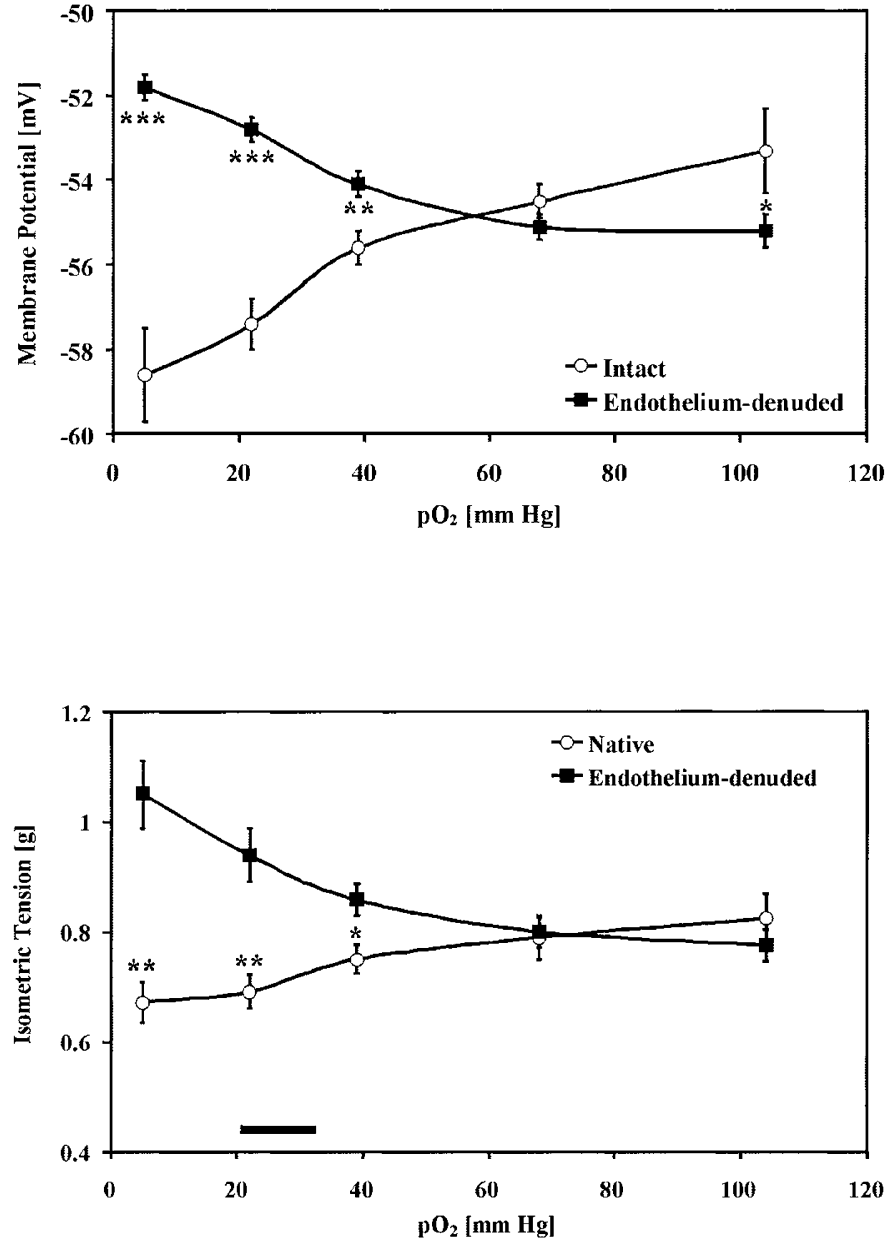

Figure 1. Oxygen-dependent regulation of membrane potential and vascular tone of untreated intact and endothelium-denuded human umbilical vein preparations. (Top) Membrane potential \pm SEM of intact $(\bigcirc ; n=29)$ and endothelium-denuded ( $\boldsymbol{\square} ; n=23$ ) human umbilical vein preparations at $\mathrm{PO}_{2}$ values between 5 and $104 \mathrm{~mm} \mathrm{Hg}$. $* * p<0.0001,{ }^{*} p<0.005,{ }^{*} p<0.05$, intact $v s$ endothelium-denuded preparations. (Bottom) Isometric tension \pm SEM of intact $(\bigcirc ; n=29)$ and endothelium-denuded $(\boldsymbol{\square} ; n=23)$ human umbilical vein preparations at $\mathrm{PO}_{2}$ values between 5 and $104 \mathrm{~mm} \mathrm{Hg} .{ }^{* *} p<$ $0.0001,{ }^{*} p<0.01$, intact $v s$ endothelium-denuded preparations. The horizontal bar represents the physiologic intrauterine umbilical venous $\mathrm{Po}_{2}$ range (24).

brane potential was significantly less depolarized in preparations with 6-OH-dopamine pretreatment $(p<0.05)$.

With $\mathrm{Po}_{2}$ increasing from 5 to $104 \mathrm{~mm} \mathrm{Hg}$, isometric tension of intact human umbilical vein preparations pretreated with 6-OH-dopamine $(n=5)$ increased from $0.598 \pm 0.040 \mathrm{~g}$ to $0.661 \pm 0.018 \mathrm{~g}(p<0.02 ;$ Fig. 2$)$. In contrast to untreated matched controls, isometric tension of intact human umbilical vein preparations pretreated with 6-OH-dopamine did not increase when $\mathrm{PO}_{2}$ was increased to values above the physiologic intrauterine range. Between $\mathrm{Po}_{2} 39$ and $104 \mathrm{~mm} \mathrm{Hg}$, isometric tension remained unchanged: $0.660 \pm 0.069 \mathrm{~g}$ versus $0.661 \pm$ 0.018 g. At $\mathrm{Po}_{2} 104 \mathrm{~mm} \mathrm{Hg}$, isometric tension was significantly lower in 6-OH-dopamine-pretreated preparations than in matched controls $(p<0.05)$. At $\mathrm{Po}_{2}$ values below $104 \mathrm{~mm}$ $\mathrm{Hg}(68,39,22$, and $5 \mathrm{~mm} \mathrm{Hg})$, isometric tension developed by intact preparations pretreated with 6-OH-dopamine was not different from that developed by intact controls. As in untreated 

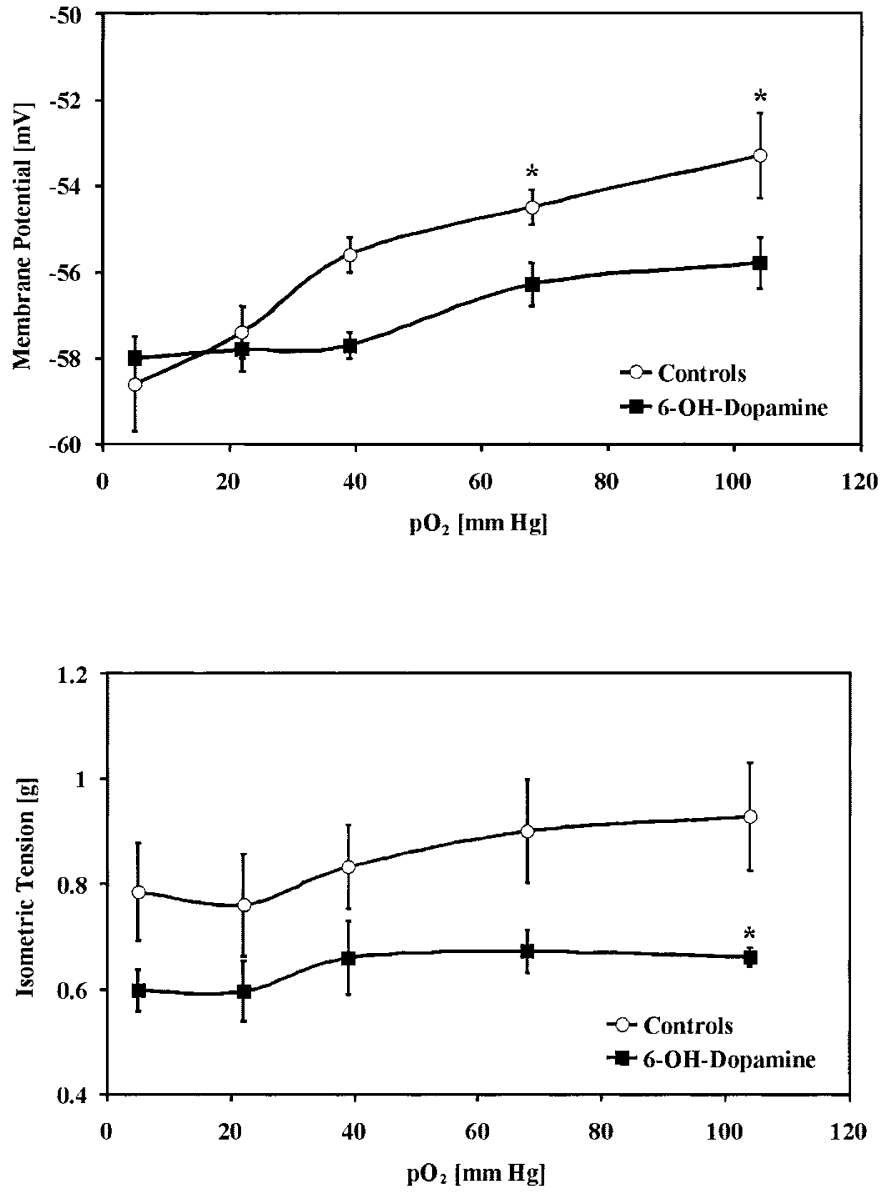

Figure 2. Effect of functional adrenergic denervation on oxygen-dependent membrane potential and vascular tone of intact human umbilical vein preparations. (Top) Membrane potential \pm SEM of intact human umbilical vein preparations with $(\square ; n=5)$ and without $(\bigcirc ; n=29$, same as in Fig. 1, top $)$ 6-OH-dopamine pretreatment at $\mathrm{PO}_{2}$ values between 5 and $104 \mathrm{~mm} \mathrm{Hg}$. ${ }^{*} p<$ 0.05 , intact preparations pretreated with $6-\mathrm{OH}$-dopamine $v s$ controls. (Bottom) Isometric tension \pm SEM developed by matched pairs of intact human umbilical vein preparations with $(\boldsymbol{\square} ; n=5)$ and without $(\bigcirc ; n=5)$ 6-OH-dopamine pretreatment at $\mathrm{PO}_{2}$ values between 5 and $104 \mathrm{~mm} \mathrm{Hg}$. ${ }^{*} p<$ 0.05 , intact preparations pretreated with $6-\mathrm{OH}$-dopamine $v s$ controls.

intact preparations, there was a linear overall correlation between isometric tension and intracellular membrane potential at all $\mathrm{PO}_{2}$ values investigated in intact preparations pretreated with 6-OH-dopamine $\left(\mathrm{y}=0.027 \mathrm{x}+2.19, r^{2}=0.54\right.$, data not shown graphically).

\section{Endothelium-Denuded Human Umbilical Vein Preparations}

Untreated endothelium-denuded preparations. With $\mathrm{PO}_{2}$ increasing from 5 to $104 \mathrm{~mm} \mathrm{Hg}$, smooth muscle cell membranes of untreated endothelium-denuded human umbilical vein preparations $(n=23)$ hyperpolarized from $-51.8 \pm 0.3$ $\mathrm{mV}$ to $-55.2 \pm 0.4 \mathrm{mV}(p<0.0001)$, most of the hyperpolarization occurring between 5 and $39 \mathrm{~mm} \mathrm{Hg}(-51.8 \pm 0.3$ $\mathrm{mV}$ versus $-54.1 \pm 0.3 \mathrm{mV} ; p<0.0001$; Fig. 1). Correspondingly, isometric tension decreased from $1.051 \pm 0.062 \mathrm{~g}$ to $0.776 \pm 0.029 \mathrm{~g}(p<0.0005)$. There was a linear overall correlation between isometric tension and intracellular mem- brane potential of the endothelium-denuded preparations at all $\mathrm{PO}_{2}$ values investigated $\left(\mathrm{y}=0.075 \mathrm{x}+4.93, r^{2}=0.98\right.$, data not shown graphically).

Endothelium-denuded preparations pretreated with 6-OHdopamine. Endothelium-denuded human umbilical vein preparations pretreated with 6-OH-dopamine $(n=5)$ showed smooth muscle cell membrane hyperpolarization with increasing $\mathrm{Po}_{2}$ similar to the hyperpolarization of untreated preparations (Fig. 3). With increasing $\mathrm{Po}_{2}$ from 5 to $104 \mathrm{~mm} \mathrm{Hg}$, membrane potential hyperpolarized from $-52.2 \pm 0.6 \mathrm{mV}$ to $-55.4 \pm 0.8 \mathrm{mV}(p<0.005)$. Correspondingly, isometric tension decreased from $1.122 \pm 0.116 \mathrm{~g}$ to $0.881 \pm 0.055 \mathrm{~g}$. There was no statistically significant difference in isometric tension developed by matched pairs of endothelium-denuded human umbilical vein preparations with and without 6-OHdopamine pretreatment at any $\mathrm{PO}_{2}$ value investigated. Again, there was a linear overall correlation between isometric tension and intracellular membrane potential at all $\mathrm{Po}_{2}$ values investi-
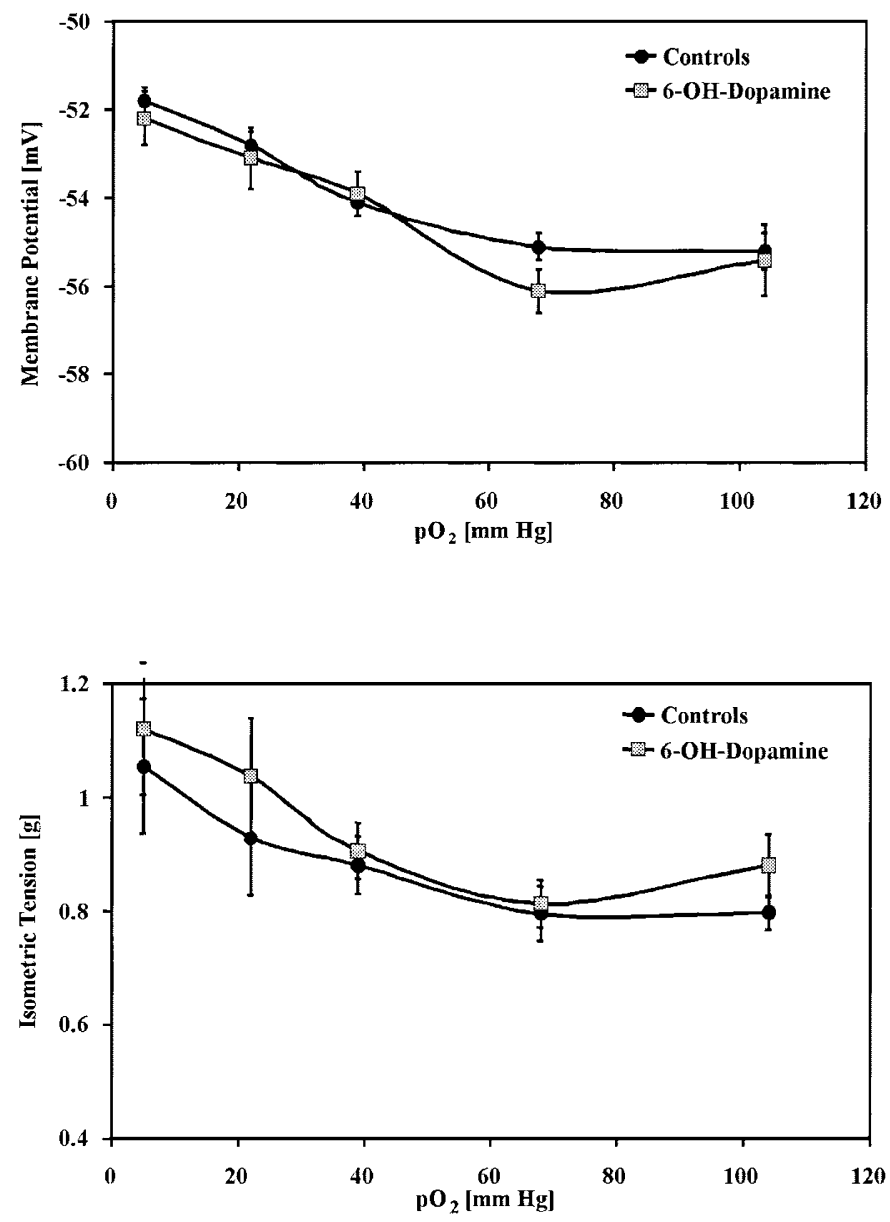

Figure 3. Effect of functional adrenergic denervation on oxygen-dependent membrane potential and vascular tone of endothelium-denuded human umbilical vein preparations. (Top) Membrane potential \pm SEM of endotheliumdenuded human umbilical vein preparations with $(\square ; n=5)$ and without $(\boldsymbol{\bullet}$; $n=23$, same as in Fig. 1, top) 6-OH-dopamine pretreatment at $\mathrm{PO}_{2}$ values between 5 and $104 \mathrm{~mm} \mathrm{Hg}$. (Bottom) Isometric tension \pm SEM developed by matched pairs of endothelium-denuded human umbilical vein preparations with $(\square ; n=5)$ and without $(\mathbf{0} ; n=5) 6-\mathrm{OH}$-dopamine pretreatment at $\mathrm{PO}_{2}$ values between 5 and $104 \mathrm{~mm} \mathrm{Hg}$. 
gated in endothelium-denuded preparations with 6-OHdopamine pretreatment $\left(\mathrm{y}=0.074 \mathrm{x}+4.98, r^{2}=0.92\right.$, data not shown graphically).

\section{DISCUSSION}

This study confirms previous results of an oxygen-dependent regulation of the human umbilical vein vascular tone that is directly related to the membrane potential of the vascular smooth muscle cells (3). The present study indicates that human umbilical vein membrane potential and vascular tone at $\mathrm{Po}_{2}$ values present under physiologic conditions and decreasing to hypoxia are independent of the influence of locally released norepinephrine. In contrast, at $\mathrm{Po}_{2}$ increasing to hyperoxia, a part of the observed membrane depolarization and increase of isometric tension can be attributed to the vasoconstricting action of endogenous norepinephrine released from the vessel wall of human umbilical vein.

Electromechanical coupling in human umbilical vein. At all $\mathrm{PO}_{2}$ values investigated between 5 and $104 \mathrm{~mm} \mathrm{Hg}$, membrane potential and isometric tension were directly related, both in intact and in endothelium-denuded human umbilical vein preparations. This was the case both in untreated and in 6-OH-dopamine-pretreated preparations and suggests electromechanical coupling as a general principle in the human umbilical vein, as demonstrated in other vascular smooth muscle $(25,26)$. Graded membrane depolarization will lead to an increased open probability of voltage-dependent $\mathrm{Ca}^{2+}$ channels, resulting in an increased influx of $\mathrm{Ca}^{2+}$ ions into the vascular smooth muscle cells. The increased intracellular $\mathrm{Ca}^{2+}$ concentration in turn leads to myosin-actin interaction and so to force development $(27,28)$.

Human umbilical vein membrane potential and tone at high $\boldsymbol{P o}_{2}$. In accordance with our hypothesis, intact preparations pretreated with 6-OH-dopamine depolarized less and developed less isometric tension at increasing $\mathrm{P}_{2}$ above the physiologic range, when compared with untreated intact controls. We therefore conclude that locally released norepinephrine, possibly in concert with ATP or neuropeptide $\mathrm{Y}$ acting as co-transmitters (29), contributes to the vasoconstriction observed in the human umbilical vein when the local $\mathrm{Po}_{2}$ increases.

However, in endothelium-denuded preparations, membrane potential and isometric tension did not differ between preparations with and without 6-OH-dopamine pretreatment. With respect to the results obtained from intact preparations, these findings are difficult to explain. Adrenergic nerve terminals are located in the adventitia and media of the blood vessel wall $(10,12)$, i.e. below the vascular endothelium. Given that pretreatment with 6-OH-dopamine diminished the membrane depolarization and constriction of intact human umbilical vein preparations in response to increasing $\mathrm{Po}_{2}$, one would also expect that pretreatment with 6-OH-dopamine resulted in a less depolarized membrane potential and in a diminished isometric tension of endothelium-denuded preparations with pretreatment. However, it has been described that catecholamines, apart from their predominant vasoconstricting effects through stimulation of $\alpha$-adrenoreceptors on vascular smooth muscle cells, are able to induce both release of vasoconstricting ATP (30) and release of vasodilating nitric oxide (31) through stimulation of adrenoreceptors located on vascular endothelial cells. Thus, our observation that oxygen-dependent changes in vascular tone did not differ between endothelium-denuded preparation with and without adrenergic denervation may be because removal of the endothelium removed both vasodilating and vasoconstricting adrenoreceptor-mediated functions of the endothelium.

Human umbilical vein membrane potential and tone at low $\boldsymbol{P o}_{2}$. Our results confirm that human umbilical vein has an endothelium-dependent vasodilator reserve (3) that may allow maintenance of an appropriate placental-fetal oxygen transport via a reduced resistance to flow at hypoxic conditions. However, because placental-fetal oxygen transport also depends on factors other than umbilical venous tone, we refrain from further speculations based on an in vitro model.

Locally released norepinephrine does not abolish the hypoxic vasodilator reserve of the human umbilical vein. Neither the hyperpolarization and vasodilatation of intact human umbilical vein preparations nor the depolarization and vasoconstriction of endothelium-denuded preparations at low $\mathrm{PO}_{2}$ were altered by functional adrenergic denervation. The hypoxic vasoconstriction of endothelium-denuded preparations, if not from endogenous norepinephrine, may instead result from vascular smooth muscular factors [e.g. vasoconstricting prostanoids $(32,33)]$ and deserves further study. An alternative explanation is that an inhibition of voltage-dependent potassium channels $\left(\mathrm{K}_{\mathrm{v}}\right.$ channels) contribute to the hypoxic depolarization and increase in isometric tension observed in endothelium-denuded preparations with or without functional adrenergic denervation $(34,35)$.

Adrenergic innervation of human umbilical vein. The question of whether human umbilical cord vessels are provided with autonomic innervation has been investigated with conflicting results in histologic studies since the early 19th century (10). The current opinion that neural elements are absent in the umbilical cord, at least in the extracorporeal part of the umbilical vessels distant from the umbilical ring, is supported by anatomical studies $(11,13-15)$, although neural fibers have been demonstrated in human umbilical cord vessels by a modified methylene blue immersion technique (12). However, we found only two functional studies on the activity of putative autonomic nerves in the human umbilical vessels by electrical stimulation, with opposite results $(13,25)$. Functional adrenergic denervation of human umbilical vein - as in our approach - has not been studied. The results of our functional study provide indirect evidence for the presence of adrenergic nerve terminals in the extracorporeal part of the human umbilical vein.

\section{CONCLUSION}

In summary, our study confirms an oxygen-dependent regulation of vascular tone of the human umbilical vein on the basis of electromechanical coupling. Our study demonstrates the contribution of locally released norepinephrine to the hyperoxic depolarization and vasoconstriction of human umbili- 
cal vein and suggests the presence of adrenergic nerve terminals in the human umbilical vein vessel wall.

\section{REFERENCES}

1. Goodwin JW 1968 The impact of the umbilical circulation on the fetus. Am J Obstet Gynecol 100:461-471

2. Paulick RP, Meyers RL, Rudolph AM 1991 Vascular responses of umbilical-placental circulation to vasodilators in fetal lambs. Am J Physiol 261:H9-H14

3. Mildenberger E, Siegel G, Versmold HT 1999 Oxygen-dependent regulation of membrane potential and vascular tone of human umbilical vein. Am J Obstet Gyneco 181:696-700

4. Moncada S, Gryglewski RJ, Bunting S, Vane JR 1976 An enzyme isolated from arteries transforms prostaglandin endoperoxides to an unstable substance that inhibits platelet aggregation. Nature 263:663-665

5. Palmer RMJ, Ferrige AG, Moncada S 1987 Nitric oxide release accounts for the biological activity of endothelium-derived relaxing factor. Nature 327:524-526

6. Feletou M, Vanhoutte PM 1988 Endothelium-dependent hyperpolarization of canine coronary smooth muscle. Br J Pharmacol 93:514-524

7. Siegel G, Schnalke F, Schaarschmidt J, Müller J, Hetzer R 1991 Hypoxia and vascular tone in normal and arteriosclerotic human coronary arteries. J Vasc Med Bio $3: 140-149$

8. Lüscher TF, Oemar BS, Boulanger CM, Hahn AWA 1993 Molecular and cellular biology of endothelin and its receptors - part I. J Hypertens 11:7-11

9. Aprigliano O, Hermsmeyer K 1976 In vitro denervation of the portal vein and caudal artery of the rat. J Pharmacol Exp Ther 198:568-577

10. Spivack M 1943 On the presence or absence of nerves in the umbilical vessels of man and guinea pig. Anat Rec 85:85-109

11. Ehinger B, Gennser G, Owman C, Persson H, Sjöberg NO 1968 Histochemical and pharmacological studies on amine mechanisms in the umbilical cord, umbilical vein and ductus venosus of the human fetus. Acta Physiol Scand 72:15-24

12. Fox H, Jacobson HN 1969 Innervation of the human umbilical cord and umbilica vessels. Am J Obstet Gynecol 103:384-389

13. Hollingsworth M 1974 Electrical stimulation and drug responses of isolated human umbilical blood vessels. Eur J Pharmacol 27:141-144

14. Reilly FD, Russell PT 1977 Neurohistochemical evidence supporting an absence of adrenergic and cholinergic innervation in the human placenta and umbilical cord. Anat Rec 188:277-286

15. Sexton AJ, Turmaine M, Cai WQ, Burnstock G 1996 A study of the ultrastructure of developing human umbilical vessels. J Anat 188:75-85

16. McIntyre CA, Williams BC, Lindsay RM, McKnight JA, Hadoke PWF 1998 Preservation of vascular function in rat mesenteric resistance arteries following cold storage, studied by small vessel myography. Br J Pharmacol 123:1555-1560

17. Mildenberger E, Biesel B, Siegel G, Versmold HT 2003 Nitric oxide and endothelin in the oxygen-dependent regulation of vascular tone of human umbilical vein. Am J Physiol 285:H1730-H1737
18. Altura BM, Molaviya D, Reich CF, Orkin LR 1972 Effects of vasoactive agents on isolated human umbilical arteries and veins. Am J Physiol 222:345-355

19. Hermsmeyer K 1980 Electrophysiology of vascular smooth muscle. In: Kaley G, Altura BM (eds) Microcirculation, Vol 3. University Park Press, Baltimore, pp $439-459$

20. Woodbury JW, McIntyre DM 1954 Electrical activity of single muscle cells of pregnant uteri studied with intracellular ultramicroelectrodes. Am J Physiol 177:355-

21. Bregestovski P, Bakhramov A, Danilov S, Moldobaeva A, Takeda K 1988 Histamineinduced inward currents in cultured endothelial cells from human umbilical vein. Br J Pharmacol 95:429-436

22. Vargas FF, Caviedes PF, Grant DS 1994 Electrophysiological characteristics of cultured human umbilical vein endothelial cells. Microvasc Res 47:153-165

23. Liu ZG, Ge ZD, He GW 2000 Difference in endothelium-derived hyperpolarizing factor-mediated hyperpolarization and nitric oxide release between human internal mammary artery and saphenous vein. Circulation 102(suppl 3):III296-III301

24. Karck U, Breckwoldt M 1996 Functions of the placenta. In: Greger R, Windhorst U (eds) Comprehensive Human Physiology: From Cellular Mechanisms to Integration, Vol 2. Springer, Berlin, pp 2291-2305

25. Somlyo AV, Somlyo AP 1968 Electromechanical and pharmacomechanical coupling in vascular smooth muscle. J Pharmacol Exp Ther 159:129-145

26. Harder DR 1982 Membrane electrical activation of arterial smooth muscle. In: Cras MF, Barnes CD (eds) Vascular Smooth Muscle: Metabolic, Ionic, and Contractile Mechanisms. Academic Press, New York, pp 71-97

27. Nelson MT, Patlak JB, Worly JF, Standen NB 1990 Calcium channels, potassium channels, and voltage-dependence of arterial smooth muscle tone. Am J Physio 259:C3-C18

28. Gollasch M, Nelson MT 1997 Voltage-dependent $\mathrm{Ca}^{2+}$ channels in arterial smooth muscle cells. Kidney Blood Press Res 20:355-371

29. Burnstock G 1990 Local mechanisms of blood flow control by perivascular nerves and endothelium. J Hypertens 8(suppl 7):S95-S106

30. Shinozuka K, Hashimoto M, Masumura S, Bjur RA, Westfall DP, Hattori K 1994 In vitro studies of release of adenine nucleotides and adenosine from rat vascular endothelium in response to $\alpha 1$-adrenoreceptor stimulation. Br J Pharmacol 113:12031208

31. Filippi S, Parenti A, Donnini S, Granger HJ, Fazzini A, Ledda F $2001 \alpha_{1 D^{-}}$ Adrenoreceptors cause endothelium-dependent vasodilatation in the rat mesenteric vascular bed. J Pharmacol Exp Ther 296:869-875

32. Ody C, Seillan C, Russo-Marie F 1982 6-ketoprostaglandin $\mathrm{F}_{1 \alpha}$, prostaglandins $\mathrm{E}_{2}$ $\mathrm{F}_{2 \alpha}$ and thromboxane $\mathrm{B}_{2}$ production by endothelial cells, smooth muscle cells and fibroblasts cultured from piglet aorta. Biochim Biophys Acta 712:103-110

33. Soler M, Camacho M, Escudero JR, Iñiguez MA, Vila L 2000 Human vascula smooth muscle cells but not endothelial cells express prostaglandin E synthase. Circ Res 87:504-507

34. Brayden JE 1996 Potassium channels in vascular smooth muscle. Clin Exp Pharmacol Physiol 23:1069-1076

35. Hampl V, Bíbová J, Straòák Z, Wu X, Michelakis E, Hashimoto K, Archer SL 2002 Hypoxic fetoplacental vasoconstriction in humans is mediated by potassium channel inhibition. Am J Physiol 283:H2440-H2449 